\title{
21. THE MEASUREMENT OF DISSOLUTION RATES OF SYNTHETIC CALCITE AND CALCAREOUS OOZE FROM DEEP SEA DRILLING PROJECT SITE 506 ${ }^{1}$
}

\author{
Hiroshi Kutsukake, Ocean Research Institute, University of Tokyo, Nakano, Tokyo, Japan
}

\begin{abstract}
Dissolution rates of calcareous ooze were measured for samples from Deep Sea Drilling Project (DSDP) Site 506, which is in the area of the Galapagos Spreading Center. Using the free-drift method, measurements were carried out at $25^{\circ} \mathrm{C}$ and atmospheric pressure. No significant difference in dissolution rates was found among the samples from three holes. However, in the present samples, the concentration of carbonate ion in seawater that is in equilibrium with calcite is 20 to $30 \%$ greater than is the case with synthetic calcite. That is, the dissolution rate of calcite under nearequilibrium conditions is greater than that of either synthetic calcite or sediments from the central Pacific (Morse, 1978). These results are consistent with field evidence indicating that the calcium carbonate compensation depth in the Galapagos region is shallower than in most other Pacific regions (Berger et al., 1976).
\end{abstract}

\section{INTRODUCTION}

The fact that the calcium carbonate compensation depth (CCD) in the equatorial region is deeper than in other regions of the Pacific Ocean is usually attributed to the high production of calcium carbonate, which is related to upwelling in this region (Adelseck and Berger, 1975). However, the CCD in the Galapagos region is only about 3600 meters, significantly shallower than in other equatorial regions in the Pacific (Berger et al., 1976).

It is, therefore, of interest to investigate the calcareous sediments in this region. In this chapter, the dissolution rates of the sediments from Site 506 (where water depth is about $2710 \mathrm{~m}$ ) were measured and compared to the previous results of Morse (1978). The dissolution rate of synthetic calcite was also measured in order to check the measurement procedure and to compare this rate with that for natural materials.

\section{SAMPLE PREPARATION AND EXPERIMENTAL METHOD}

Surface seawater from the North Pacific was used for our experiments. According to the Preliminary Report of Hakuhō Maru Cruise KH-70-1 (Horibe, 1970), the salinity and the alkalinity in this region are $35 \%$ and 2.3 to $2.4 \mathrm{meq} / \mathrm{l}$, respectively. The seawater was passed through a $(0.45)$ Millipore filter to remove suspended materials.

For the synthetic calcite experiment, pure analytical-grade $\mathrm{CaCO}_{3}$ powder was used. The grain size of the powder was estimated to be $4 \pm 2 \mu \mathrm{m}$ based on observations made with the optical microscope. The calcareous sediments used in the experiments were samples from DSDP Site 506 (506-2-2, 506B-2-2, and 506B-3-2). The two selected holes are located, respectively, on a mound (Hole 506B) and in an offmound region (Hole 506). These samples were soaked in water to separate out the clay minerals, with sediment particles between $37 \mu \mathrm{m}$ and $105 \mu \mathrm{m}$ being selected. Microscopic observation revealed that most of the sediments are foraminifers and foraminifer fragments. Small amounts of radiolarians and diatoms were also observed. These samples were purified by an ultrasonic cleaner in distilled water.

Dissolution rates were measured by the free-drift method (Sjöberg, 1976; Plummer et al.. 1978), in which, after introducing calcite into a solution, variation of $\mathrm{pH}$ is measured over time. The rate of increase

\footnotetext{
${ }^{1}$ Honnorez, J., Von Herzen, R. P., et al., Init. Repts. DSDP, 70: Washington (U.S. Govt. Printing Office).
}

in $\mathrm{pH}$ was converted into the dissolution rate by the following method. First the $\mathrm{pH}$ values of seawater containing various preweighed amounts of synthetic calcite were measured under various $P_{\mathrm{CO}_{2}}$ conditions ranging from $10^{-2}$ to $10^{\circ} \mathrm{atm}$. The results are expressed by the following equation,

$$
W_{\mathrm{CaCO}_{3}}(\mathrm{mg})=A \cdot P_{\mathrm{CO}_{2}} / a_{\mathrm{H}^{+}}+B,
$$

where $W_{\mathrm{CaCO}_{3}}$ is the amount of calcite introduced into the seawater. The hydrogen ion activity corresponding to $\mathrm{pH}$ is denoted as $a_{\mathrm{H}^{+}}$. This equation is derived from charge balance,

$$
2 m_{\mathrm{Ca}^{++}}+m_{\mathrm{H}^{+}}=m_{\mathrm{HCO}_{3}}{ }^{-}+2 m_{\mathrm{CO}_{3}}{ }^{--}+m_{\mathrm{OH}^{-}}+\text {constant, (2) }
$$

where $m_{\mathrm{Ca}^{++}} m_{\mathrm{H}^{+}}, m_{\mathrm{HCO}_{3}}^{-}, m_{\mathrm{CO}_{3}}^{--}$, and $m_{\mathrm{OH}^{-}}$are the concentrations of calcium ions, hydrogen ions, bicarbonate ions, carbonate ions, and hydroxide ions, respectively. Assuming that the increase in calcium ions stemming from calcite dissolution nearly equals the increase of bicarbonate ions, and that changes in the concentrations of the other ions can be neglected, equation 1 can be derived. The values of $A$ and $B$ in equation 1 are constant and can be determined from the slope and the intercept on plots of $P_{\mathrm{CO}_{2}} / a_{\mathrm{H}}{ }^{+}$versus additional calcite. The product of the equilibrium constants $K_{0}$ and $K_{1}$, which are defined by

$$
\begin{gathered}
K_{0}=m_{\mathrm{H}_{2} \mathrm{CO}_{3}} / P_{\mathrm{CO}_{2}} \\
K_{1}=a_{\mathrm{H}}+\cdot m_{\mathrm{HCO}_{3}}-/ m_{\mathrm{H}_{2} \mathrm{CO}_{3}}
\end{gathered}
$$

was obtained from $A$. In these equations $m_{\mathrm{H}_{2} \mathrm{CO}_{3}}$ and $m_{\mathrm{HCO}_{3}}$ - denote the concentrations of carbonic acid and the bicarbonate ion, respectively. Combining the estimated value $K_{0}$, after Murray and Riley (1971), and the obtained value $A$, the first dissociation constant of carbonate acid, $K_{1}$, was estimated as $1.09 \times 10^{-6}$, which is in good agreement with the value arrived at by Berner and Morse (1974). The calculations of dissolution rates and bicarbonate ion concentrations in this chapter are made using these two variables.

The value that was used (after Mehrbach et al., 1973) for the second dissociation constant, $K_{2}$, is defined by the expression,

$$
K_{2}=a_{\mathrm{H}^{+}} \cdot m_{\mathrm{CO}_{3}}{ }^{--/} / m_{\mathrm{HCO}_{3}}{ }^{-} .
$$

This value is not necessary in converting $\mathrm{pH}$ values into dissolution rates, but it is used to obtain the concentration of the carbonate ions corresponding to each $\mathrm{pH}$ value.

The $1000 \mathrm{ml}$ solution used to dissolve calcite was placed in a Pyrex flask and immersed in a thermostatic bath whose temperature was kept at $25 \pm 0.1^{\circ} \mathrm{C}$. A mixture of $\mathrm{N}_{2}$ and $\mathrm{CO}_{2}$ gases was bubbled into the reaction flask to keep $P_{\mathrm{CO}_{2}}$ constant at the desired value. This gas was also passed through the $10^{-2} \mathrm{~mol} / 1 \mathrm{Na}_{2} \mathrm{CO}_{3}$ solution of the same 
temperature. The partial pressure of $\mathrm{CO}_{2}$ is calculated from the $p \mathrm{H}$ value of the $\mathrm{Na}_{2} \mathrm{CO}_{3}$ solution based on the extended Debye-Hückel equation.

The measurement of dissolution rates was carried out under $P_{\mathrm{CO}_{2}}$ $=10^{-1} \mathrm{~atm}$. for the synthetic calcite and $P_{\mathrm{CO}_{2}}=10^{-2} \mathrm{~atm}$. for the synthetic calcite and the Galapagos sediments. Since the dissolution of calcite consumes $\mathrm{CO}_{2}$ in the solution (Plummer et al., 1978), the disequilibrium between the liquid and gas interface arises especially under the low $P_{\mathrm{CO}_{2}}$ condition $\left(10^{-2}\right.$ atm.). This slightly influences the dissolution rate and the carbonate ion concentration calculated from the measured rate of $\mathrm{pH}$ increase. To correct for this effect, the $\mathrm{CO}_{2}$ transfer rate is experimentally measured under the same conditions as is the dissolution rate measurement. The correction is rather minor for synthetic calcite under $10^{-2}$ atm. $P_{\mathrm{CO}_{2}}$. Several hundred milligrams of sample were used for each experiment.

\section{RESULT}

The experimental results for synthetic calcite are summarized in Table 1 and Figure 1. The dissolution rate was calculated using the assumption that each calcite grain has a uniform size equal to the mean value. The specific surface area of the synthetic calcite, determined from the mean grain size $\left(5.56 \times 10^{-1} \mathrm{~m}^{2} / \mathrm{g}\right)$, is similar to the samples used by Sjöberg (1976). The dissolution rates under the near-equilibrium condition is plotted in Figure 1 as a function of carbonate ion con-

Table 1. Dissolution rate of synthetic calcite in seawater.

\begin{tabular}{|c|c|c|c|c|}
\hline$\underset{\text { (gas) }}{\mathrm{PCO}_{2}}$ & $\underset{(\mathrm{mg})}{\mathrm{CaCO}_{3}}$ & $p \mathrm{H}$ & $\begin{array}{c}\text { Rate } \\
\left(\mathrm{mg} / \mathrm{cm}^{2} / \mathrm{y} .\right)\end{array}$ & $\underset{\text { (solution) }}{\mathrm{P}_{\mathrm{CO}}}$ \\
\hline \multirow[t]{7}{*}{$1.1 \times 10^{-2}$} & 400 & 6.950 & 95.42 & $1.03 \times 10^{-2}$ \\
\hline & & 6.971 & 83.02 & $1.01 \times 10^{-2}$ \\
\hline & & 6.992 & 77.62 & $1.01 \times 10^{-2}$ \\
\hline & & 7.012 & 59.41 & $1.02 \times 10^{-2}$ \\
\hline & & 7.032 & 41.78 & $1.03 \times 10^{-2}$ \\
\hline & & 7.053 & 21.59 & $1.05 \times 10^{-2}$ \\
\hline & & 7.070 & 11.60 & $1.06 \times 10^{-2}$ \\
\hline \multirow[t]{10}{*}{$1.1 \times 10^{-2}$} & 800 & 6.960 & 101.40 & $1.01 \times 10^{-2}$ \\
\hline & & 6.980 & 99.64 & $9.72 \times 10^{-3}$ \\
\hline & & 7.000 & 100.60 & $9.44 \times 10^{-3}$ \\
\hline & & 7.020 & 90.82 & $9.25 \times 10^{-3}$ \\
\hline & & 7.040 & 68.89 & $9.39 \times 10^{-3}$ \\
\hline & & 7.060 & 36.76 & $9.88 \times 10^{-3}$ \\
\hline & & 7.080 & 17.60 & $1.02 \times 10^{-2}$ \\
\hline & & 7.100 & 4.71 & $1.04 \times 10^{-2}$ \\
\hline & & 7.120 & 2.46 & $1.04 \times 10^{-2}$ \\
\hline & & 7.140 & 1.95 & $1.04 \times 10^{-2}$ \\
\hline \multirow{15}{*}{$1.1 \times 10^{-1}$} & 800 & 5.940 & 862.00 & $1.11 \times 10^{-1}$ \\
\hline & & 5.960 & 874.00 & $1.09 \times 10^{-1}$ \\
\hline & & 6.000 & 793.00 & $1.07 \times 10^{-1}$ \\
\hline & & 6.040 & 896.00 & $1.05 \times 10^{-1}$ \\
\hline & & 6.080 & 762.00 & $1.04 \times 10^{-1}$ \\
\hline & & 6.120 & 684.00 & $1.05 \times 10^{-1}$ \\
\hline & & 6.165 & 566.00 & $1.03 \times 10^{-1}$ \\
\hline & & 6.210 & 517.00 & $1.03 \times 10^{-1}$ \\
\hline & & 6.250 & 436.00 & $1.05 \times 10^{-1}$ \\
\hline & & 6.293 & 365.70 & $1.06 \times 10^{-1}$ \\
\hline & & 6.340 & 294.40 & $1.06 \times 10^{-1}$ \\
\hline & & 6.380 & 244.10 & $1.07 \times 10^{-1}$ \\
\hline & & 6.400 & 178.70 & $1.10 \times 10^{-1}$ \\
\hline & & 6.420 & 113.50 & $1.10 \times 10^{-1}$ \\
\hline & & 6.440 & 106.40 & $1.11 \times 10^{-1}$ \\
\hline \multirow{15}{*}{$1.1 \times 10^{-1}$} & 1600 & 6.000 & 790.00 & $1.07 \times 10^{-1}$ \\
\hline & & 6.040 & 733.00 & $1.04 \times 10^{-1}$ \\
\hline & & 6.080 & 736.00 & $1.02 \times 10^{-1}$ \\
\hline & & 6.120 & 731.00 & $9.96 \times 10^{-2}$ \\
\hline & & 6.160 & 686.00 & $9.79 \times 10^{-2}$ \\
\hline & & 6.200 & 611.00 & $9.66 \times 10^{-2}$ \\
\hline & & 6.240 & 584.00 & $9.57 \times 10^{-2}$ \\
\hline & & 6.285 & 478.00 & $9.59 \times 10^{-2}$ \\
\hline & & 6.330 & 402.00 & $9.75 \times 10^{-2}$ \\
\hline & & 6.370 & 329.00 & $9.96 \times 10^{-2}$ \\
\hline & & 6.413 & 240.70 & $1.03 \times 10^{-1}$ \\
\hline & & 6.455 & 125.60 & $1.07 \times 10^{-1}$ \\
\hline & & 6.477 & 97.40 & $1.08 \times 10^{-1}$ \\
\hline & & 6.498 & 55.90 & $1.09 \times 10^{-1}$ \\
\hline & & 6.520 & 29.30 & $1.10 \times 10^{-1}$ \\
\hline
\end{tabular}

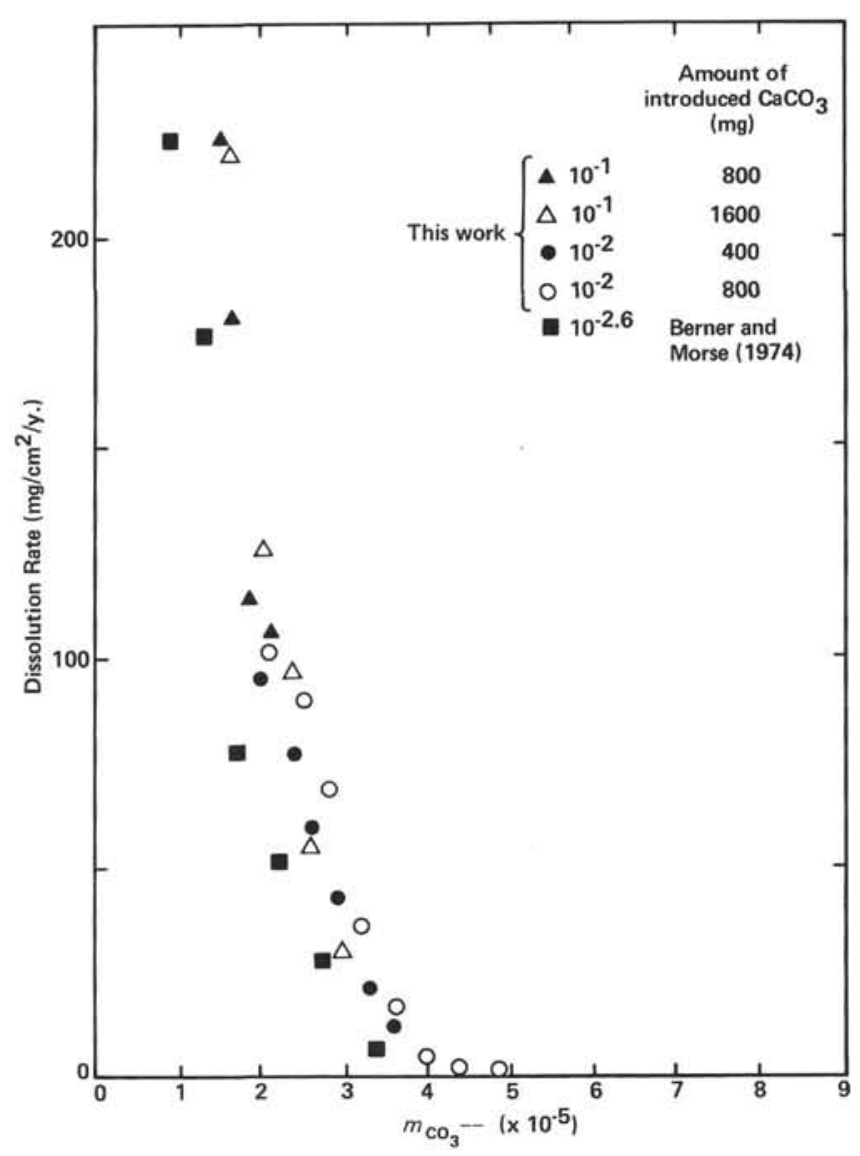

Figure 1. Dissolution rate vs. carbonate ion concentration for synthetic calcite under near-equilibrium conditions. Results by Berner and Morse (1974) are also plotted.

centration. This figure shows that the dissolution rate depends mainly on carbonate ion concentration and is independent of $P_{\mathrm{CO}_{2}}$. This tendency qualitatively agrees with some previous work (e.g., that of Berner and Morse, 1974; Plummer et al., 1978). The absolute values of dissolution rates are slightly different from previous data collected by Berner and Morse (1974), also shown in the same figure. However, this discrepancy is within the degree of uncertainty of the specific surface area.

The results for the Galapagos sediments are given in Table 2 and Figure 2, in which dissolution rates are plotted against the carbonate ion concentration, along with the results of Morse (1978). No significant differences can be found among dissolution rates for the three different samples from Site 506. It is interesting, however, that the general trend of the Galapagos samples is significantly different from that of the sediments analyzed from other Pacific regions (Morse, 1978), i.e., the dissolution rates of the central Pacific sediments decrease sharply with increasing $m_{\mathrm{CO}_{3}--}$, and the equilibrium concentration at which the dissolution rate vanishes is nearly equal for both central Pacific sediments and synthetic calcite. In contrast, the equilibrium value of $m_{\mathrm{CO}_{3}-}$ - for the sediments from the Galapagos region is $20 \%$ to $30 \%$ larger than that for synthetic calcite and the central Pacific sediments. 


\section{DISCUSSION}

Table 2. Dissolution rate of sediments from the Galapagos region.

\begin{tabular}{ccrc}
\hline Section & pH & $\begin{array}{c}\text { Rate } \\
(\% / \text { day })\end{array}$ & $\begin{array}{c}P_{\mathrm{CO} 2} \\
\text { (solution) }\end{array}$ \\
\hline 506-2-2 & 6.990 & 18.03 & $1.20 \times 10^{-2}$ \\
& 7.011 & 17.40 & $1.20 \times 10^{-2}$ \\
& 7.031 & 14.00 & $1.20 \times 10^{-2}$ \\
& 7.052 & 8.72 & $1.21 \times 10^{-2}$ \\
& 7.072 & 11.20 & $1.20 \times 10^{-2}$ \\
& 7.092 & 5.56 & $1.21 \times 10^{-2}$ \\
& 7.112 & 2.46 & $1.21 \times 10^{-2}$ \\
& 7.120 & 2.44 & $1.21 \times 10^{-2}$ \\
506B-2-2 & 7.030 & 32.60 & $1.19 \times 10^{-2}$ \\
& 7.050 & 14.96 & $1.20 \times 10^{-2}$ \\
& 7.070 & 9.42 & $1.20 \times 10^{-2}$ \\
& 7.090 & 14.02 & $1.20 \times 10^{-2}$ \\
& 7.110 & 5.85 & $1.20 \times 10^{-2}$ \\
& 7.120 & 4.20 & $1.21 \times 10^{-2}$ \\
$506 \mathrm{~B}-3-2$ & 7.060 & 7.75 & $1.17 \times 10^{-2}$ \\
& 7.080 & 14.03 & $1.16 \times 10^{-2}$ \\
& 7.100 & 13.06 & $1.16 \times 10^{-2}$ \\
& 7.120 & 3.73 & $1.18 \times 10^{-2}$ \\
& 7.140 & 2.89 & $1.18 \times 10^{-2}$ \\
& 7.160 & 2.24 & $1.18 \times 10^{-2}$ \\
& 7.180 & 0.87 & $1.18 \times 10^{-2}$ \\
\hline
\end{tabular}

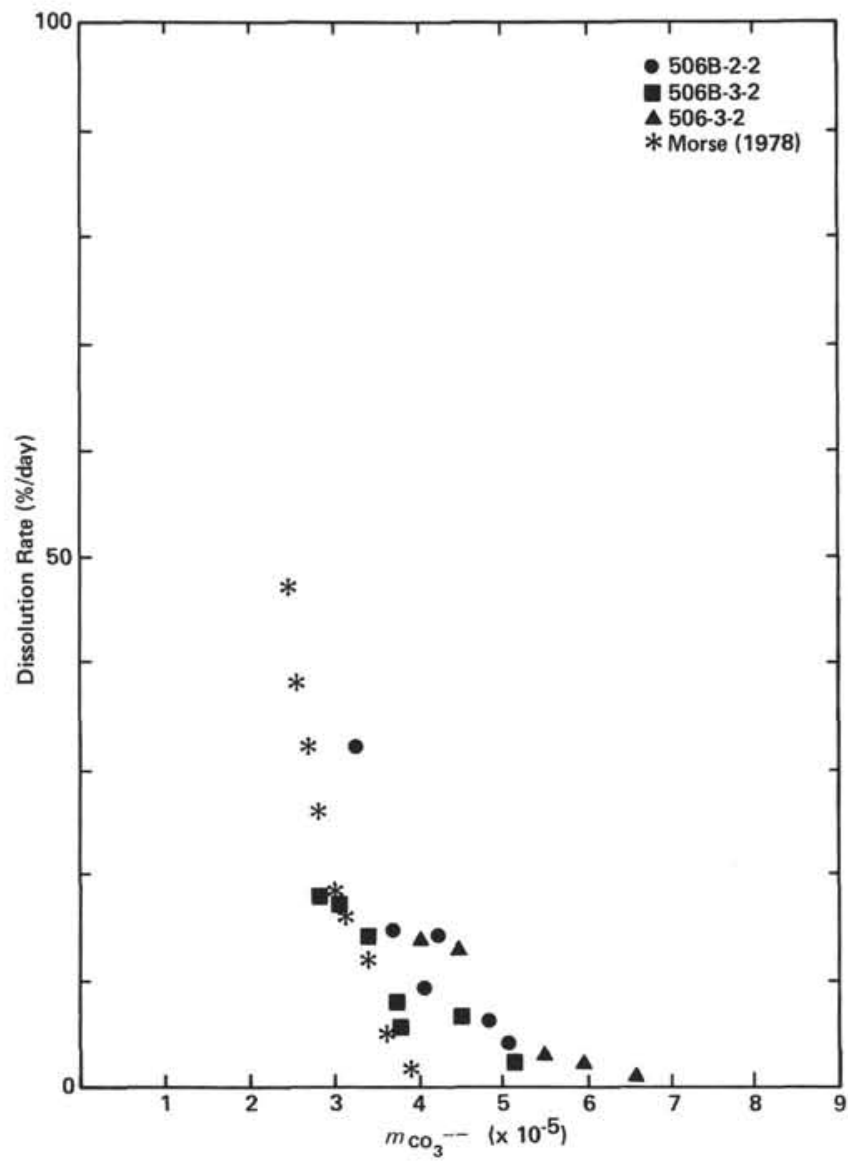

Figure 2. Dissolution rate vs. carbonate ion concentration for sediments from the Galapagos region. Results for sediments from the central Pacific, measured by Morse (1978), are also plotted.
These results on the dissolution rate of synthetic calcite are in good agreement with the previous work of Berner and Morse (1974). On the other hand, dissolution rates of sediments from the Galapagos region are significantly different from those of sediments from the central Pacific (Morse, 1978). Therefore it seems that the observed result reflects true differences in dissolution rates rather than an apparent one caused by experimental methods or by variations in seawater. These different dissolution rates are probably explained by the different chemical composition of sediment samples rather than by shape or other geometrical factors.

The apparent solubility product for the samples from the Galapagos region can be obtained by the following procedure. First, concentration of calcium ion in the seawater is correlated with salinity by the following relationship (Millero, 1974):

$$
m_{\mathrm{Ca}^{++}}=2.93 \times 10^{-4} \times \text { salinity }(\%) .
$$

Using this relationship, $m_{\mathrm{Ca}^{+}}+$in the seawater used for the experiment is estimated to be $1.03 \times 10^{-2}(\mathrm{~mol} / \mathrm{l})$ from its salinity. In this estimate the increase of $m_{\mathrm{Ca}}{ }^{++}$ caused by calcite dissolution is neglected. Combining this estimate with the equilibrium concentration of $m_{\mathrm{CO}_{3}--}$ obtained from our experiments, the apparent solubility product turns out to be $6.5 \times 10^{-7}$, which is larger than the value $5.0 \times 10^{-7}$ for pure calcite (Ingles et al., 1973). This high solubility is probably caused by the presence of magnesium in the calcite (Akin and Lagerwerff, 1964), although the effect of impurities on dissolution kinetics has not been well established.

It is likely that the high dissolution rate under nearequilibrium conditions should substantially shift the CCD. A simple proposal by Berger et al. (1976) concerning CCD is shown in Figure 3, where the vertical profiles of dissolution rates are based on present experimental data and the results of Morse (1978). The estimate of dissolution rates is based on the assumption that the rate depends only on undersaturation with respect to calcite. I have used the data on the undersaturation of seawater in the Pacific by Takahashi (1975), which is calculated from the distribution of alkalinity and total carbonate ion concentration. As shown in Figure 3, the dissolution rate at the CCD balances the supply rate and is about $10 \%$ /day in the equatorial region of the Pacific. If we assume the same supply rate in the Galapagos region as in the other equatorial regions, we can evaluate the depth at which dissolution balances supply. The results show that the CCD should be about 1000 to 2000 meters shallower in the Galapagos, which is consistent with field observation. It is thus concluded that one possible explanation for the shallower CCD in the Galapagos region is the greater solubility of sediments in this region.

\section{CONCLUSION}

There are two general conclusions to be drawn. First, that the dissolution rate of sediments from the Gala- 


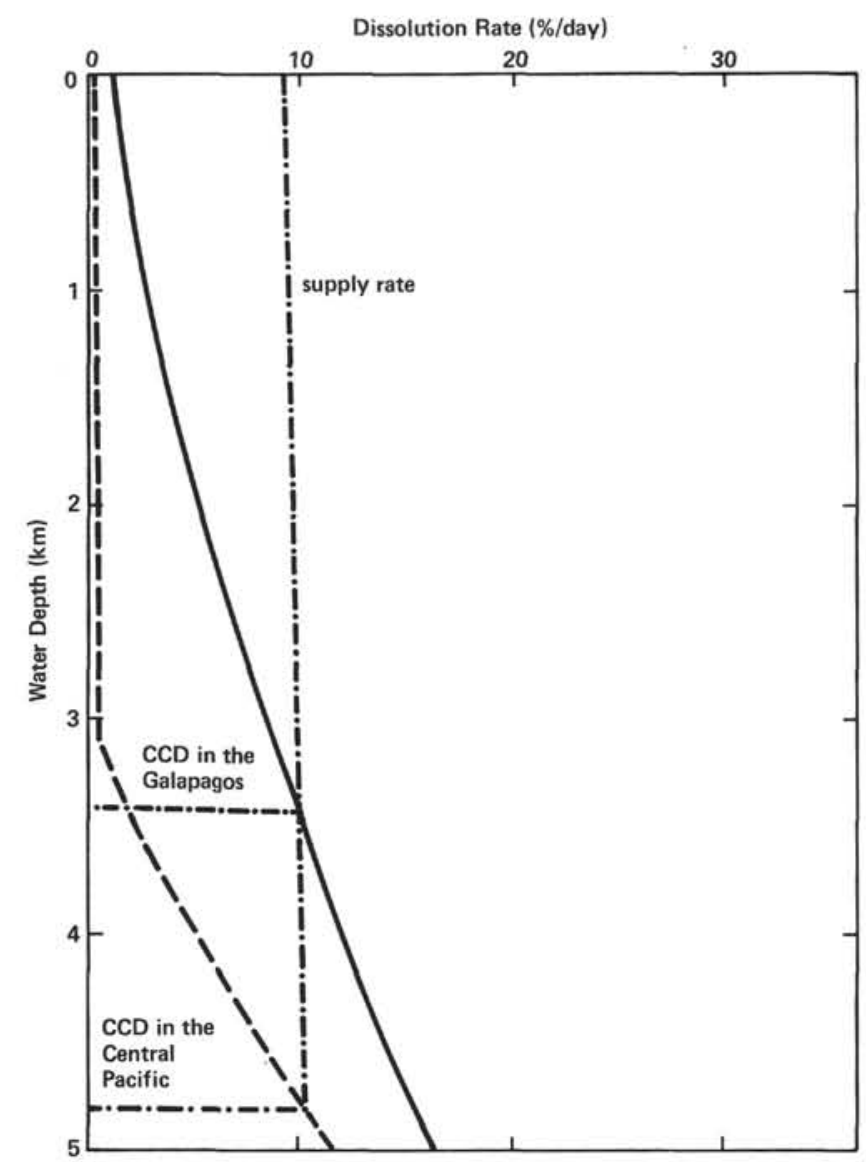

Figure 3. Simple conceptual proposal of variation in calcium carbonate compensation depth (CCD). Solid line is vertical profile of dissolution rate based on the present experimental results. Dashed line is based on the results of Morse (1978). The depth at which dissolution rate curve and supply rate curve intersect indicates CCD.

pagos region is characterized by a high equilibrium concentration of carbonate ion. This tendency is observed in all samples collected from the three different sites. Second, the shallow CCD in the Galapagos may be attributed to the greater solubility of sediments in this region, compared with that of samples from the central Pacific region.

\section{ACKNOWLEDGMENT}

I wish to thank R. Matsumoto and Y. Yanagimoto for their critical reviews and useful comments. I also wish to thank S. Karato, Y. Ida, and T. Furuta for their comments and suggestions.

\section{REFERENCES}

Adelseck, C. G., and Berger, W. H., 1975. On the dissolution of planktonic Foraminifera and associated microfossils during settling and on the seafloor. Spec. Publ. Cushman Found. Foraminiferal Res., 13:70-81.

Akin, G. W., and Lagerwerff, T. V., 1964. Calcium carbonate equilibria in solutions open to the air: Enhanced solubility of $\mathrm{CaCO}_{3}$ in presence of $\mathrm{Mg}^{2+}$ and $\mathrm{SO}_{4}{ }^{2-}$. Geochim. Cosmochim. Acta, 29: 333-337.

Berger, W. H., Adelseck, C. G., and Mayer, L. A., Jr., 1976. Distribution of carbonate in surface sediments of the Pacific Ocean. J. Geophys. Res., 81:2617-2627.

Berner, R. A., and Morse, J. W., 1974. Dissolution kinetics of calcium carbonate in seawater: IV. Theory of calcite dissolution. Am. J. Sci., 274:108-134.

Honjö, S., and Erez, J., 1978. Dissolution rates of calcium carbonate in deep ocean: an in-situ experiment in the North Atlantic-Ocean. Earth Planet. Sci. Lett., 40:287-300.

Horibe, Y., 1971. Oceanographic data. In Horibe, Y. (Ed.), Preliminary Report of the Hakuhō Maru Cruise KH-70-1: Tokyo (Ocean Research Institute), University of Tokyo.

Ingles, S. E., Culberson, C. H., Howley, J., and Pytkowicz, R. M., 1973. The solubility of calcite in seawater at atmospheric pressure and 35\% salinity. Mar. Chem., 1:295-307.

Mehrbach, C., Culberson, C. H., Hawley, J., and Pytokowicz, R. M., 1973. Measurement of the apparent dissociation constants of carbonic acid in seawater at atmospheric pressure. Limnol. Oceanog., 18:897.

Millero, F. J., 1974. Seawater as a multicomponent electrolyte solution. In Goldberg, E. D. (Ed.), The Sea (Vol. 5): New York (Interscience), pp. 3-80.

Morse, J. W., 1978. Dissolution kinetics of calcium carbonate in seawater: VI. The near-equilibrium dissolution kinetics of calcium carbonate-rich sediments. Am. J. Sci., 278:344-353.

Murray, C. N., and Riley, J. P., 1971. The solubility of gases in distilled water and seawater-4. Carbon dioxide. Deep Sea Res., 18:533-536.

Plummer, L. N., Wigley, T. M. L., and Parkhurst, D. L., 1978. The kinetics of calcite dissolution in $\mathrm{CO}_{2}$-water systems at $5^{\circ} \mathrm{C}$ and $60^{\circ} \mathrm{C}$ and 0.0 to $1.0 \mathrm{~atm} . \mathrm{CO}_{2}$. Am. J. Sci., 278:179-216.

Sjöberg, E. L., 1976. A fundamental equation for calcite dissolution kinetics. Geochim. Cosmochim. Acta, 40:441-447.

Takahashi, T., 1975. Carbonate chemistry of seawater and the calcite compensation depths in the oceans. Spec. Publ. Cushman Found. Foraminiferal Res., 13:11-26. 